\title{
Short communication: Implementation of a breeding value for heat tolerance in Australian dairy cattle
}

\author{
Thuy T. T. Nguyen, ${ }^{* 1}$ Phil J. Bowman, ${ }^{*} \dagger$ Mekonnen Haile-Mariam, ${ }^{*}$ Gert J. Nieuwhof, $\ddagger$ Benjamin J. Hayes, ${ }^{\star} \S$ \\ and Jennie E. Pryce*† \\ *Agriculture Victoria, AgriBio, Centre for AgriBioscience, Bundoora, Victoria 3083, Australia \\ †School of Applied Systems Biology, La Trobe University, Bundoora, Victoria 3083, Australia \\ $\ddagger$ DataGene, AgriBio, Centre for AgriBioscience, Bundoora, Victoria 3083, Australia \\ §Queensland Alliance for Agriculture and Food Innovation, University of Queensland, Brisbane, St Lucia, QLD 4072, Australia
}

\begin{abstract}
Excessive ambient temperature and humidity can impair milk production and fertility of dairy cows. Selection for heat-tolerant animals is one possible option to mitigate the effects of heat stress. To enable selection for this trait, we describe the development of a heat tolerance breeding value for Australian dairy cattle. We estimated the direct genomic values of decline in milk, fat, and protein yield per unit increase of temperaturehumidity index (THI) using 46,726 single nucleotide polymorphisms and a reference population of 2,236 sires and 11,853 cows for Holsteins and 506 sires and 4,268 cows for Jerseys. This new direct genomic value is the Australian genomic breeding value for heat tolerance (HT ABVg). The components of the HT ABVg are the decline in milk, fat, and protein per unit increase in THI when THI increases above the threshold of 60 . These components are weighted by their respective economic values, assumed to be equivalent to the weights applied to milk, fat, and protein yield in the Australian selection indices. Within each breed, the $\mathrm{HT} \mathrm{ABVg}$ is then standardized to have a mean of 100 and standard deviation (SD) of 5, which is consistent with the presentation of breeding values for many other traits in Australia. The HT ABVg ranged from -4 to $+3 \mathrm{SD}$ in Holsteins and -3 to $+4 \mathrm{SD}$ in Jerseys. The mean reliabilities of $\mathrm{HT}$ ABVg among validation sires, calculated from the prediction error variance and additive genetic variance, were $38 \%$ in both breeds. The range in $\mathrm{ABVg}$ and their reliability suggests that $\mathrm{HT}$ can be improved using genomic selection. There has been a deterioration in the genetic trend of HT, and to
\end{abstract}

Received March 20, 2017.

Accepted May 18, 2017.

${ }^{1}$ Corresponding author: thuy.nguyen@ecodev.vic.gov.au moderate the decline it is suggested that the HT ABVg should be included in a multitrait economic index with other traits that contribute to farm profit.

Key words: heat tolerance, genomic selection, milk production

\section{Short Communication}

Heat stress is an issue of growing concern for many livestock production systems worldwide, including the dairy industry in some regions of Australia. Heat stress affects not only animal welfare but also economic returns (Kadzere et al., 2002; St-Pierre et al., 2003). When exposed to heat stress conditions, such as high temperature and humidity, cows produce less milk due to reduced feed intake and secretory function of the udder (Silanikove, 1992). Heat stress is also known to reduce conception rates (Hansen and Aréchiga, 1999) and increase the incidence of health problems and mortality rates in dairy cows (Kadzere et al., 2002; Dikmen and Hansen, 2009).

Mitigation of heat stress can be multifaceted and includes physical protection, nutritional management, and genetic improvement (Beede and Collier, 1986). Although efforts have been made at a herd management level to provide a suitable environment for cows (i.e., shade and cooling devices) and extensive research has been conducted in nutritional management for lactating cows in hot climates (Beede and Collier, 1986; West, 1998), genetic improvement for heat tolerance (HT) has not been practiced in the dairy industry. It is, however, widely recognized that genetic variation is associated with the performance of dairy cows under heat stress conditions, making the selection for this trait possible (Bohmanova et al., 2008).

In Australia, genomic selection for HT can take advantage of the genotypes from thousands of cows and bulls already available. Nguyen et al. (2016a) used herd test-day and weather records over an 11-yr period to 
estimate tolerance to heat stress. They determined the extent of the decline in milk, fat, and protein yield as temperature-humidity index (THI) increased for Holsteins and Jerseys. Genomic EBV for HT were determined using high-density SNP data. These HT genomic EBV were also empirically validated through a heat challenge experiment in which genomically predicted heat-tolerant cows showed significantly less milk yield losses as well as lower rectal and intravaginal temperatures than the predicted heat-susceptible animals when challenged with a mild simulated heat wave (Garner et al., 2016).

Here, we describe an implementation plan of the Australian genomic breeding values for HT (HT ABVg) for Holstein and Jersey dairy cattle. Definition, expression, and methods of how breeding values for HT could be derived and implemented are presented and discussed.

Breeding values for HT can be expressed in several ways (Nguyen et al., 2016b). Following consultation with Australian dairy industry representatives, HT is expressed as the decline in milk, fat, and protein yield per unit increase in THI when THI increases above the threshold of 60 , weighted by their respective economic weights. It is then standardized to have a mean of 100 and standard deviation of 5 for each breed. This method of expressing the breeding value is typical of many breeding values evaluated for Australian dairy cattle. To calculate HT ABVg, first, SNP effects for the decline in milk, fat, and protein yield with increasing heat stress were calculated using the following steps.

(1) Calculation of phenotypes for HT for cows The data set used to calculate phenotypes for HT for cows was similar to that used by Nguyen et al. (2016a), with several improvements: (1) climate data (i.e., hourly temperature and relative humidity) were extended to include recent data (i.e., to August 2016); (2) the distance between herds and weather stations was measured using the GPS coordinates of each herd instead of its postcode centroid, where possible; and (3) herds that did not have a weather station within a $60-\mathrm{km}$ radius were excluded from analyses. A summary of the final data set is given in Table 1 . The rates of decline (slope) in milk, fat, and protein yield after a heat stress event were estimated using a reaction norm model (Nguyen et al., 2016a). In this model, data on milk, fat, or protein yield were fitted with fixed effects of herd test day, year season of calving, parity, a thirddegree polynomial on age at calving, parity $\times$ an eighth-degree polynomial on DIM, and stage of lactation $\times$ a linear polynomial on THI. Random effects included a random regression on a linear orthogonal polynomial of THI and a residual term. In the model, the threshold of THI was set to 60 following Hayes et al. (2003). The analyses were conducted using ASReml (Gilmour et al., 2009) and were done separately for Holsteins and Jerseys.

(2) Calculation of pseudophenotypes for HT for sires

Using the cow slope solutions obtained in step 1, sire slopes or daughter trait deviations (equivalent to daughter yield deviations) for decline in milk, fat, and protein yield as THI increases were estimated.

(3) Calculation of SNP effects

The SNP effects were calculated separately for the decline in milk, fat, and protein yield with increasing THI. The number of animals in the reference populations was 11,853 cows and 2,236 sires for Holsteins and 4,268 cows and 506 sires for Jerseys. The sires needed to have at least 5 daughters with phenotypes to be included in the reference sets. Genotypes for 46,726 SNP were obtained from DataGene (Melbourne, Australia) in September 2016. A genomic best linear unbiased prediction model was used to fit the daughter trait deviations obtained from step 2 (Nguyen et al., 2016a) and then back solved to obtain SNP effects. The HT ABVg were then calculated using the following steps.

Table 1. Characteristics of the data sets used in the calculation of heat tolerance phenotypes for cows

\begin{tabular}{lrrrrrrr}
\hline & \multicolumn{3}{c}{ Holstein } & & \multicolumn{3}{c}{ Jersey } \\
\cline { 2 - 3 } \cline { 7 - 8 } $\begin{array}{l}\text { Item } \\
\text { (no.) }\end{array}$ & 1st parity & 2nd parity & 3rd parity & & 1st parity & 2nd parity & 3rd parity \\
\hline Records & $2,798,669$ & $2,057,838$ & $1,319,742$ & & 591,434 & 446,438 & 309,217 \\
Herds & 1,927 & 1,841 & 1,650 & & 554 & 537 & 498 \\
Cows & 424,540 & 325,026 & 214,787 & & 84,702 & 67,451 & 47,520 \\
Sires & 10,230 & 9,476 & 8,222 & & 3,175 & 2,950 & 2,577 \\
\hline
\end{tabular}


(4) Calculation of DGV for decline in milk, fat, and protein yields ( $\mathrm{kg})$ with heat stress

The following equations were used to calculate direct genomic values (DGV) for decline in milk, fat, and protein yields $(\mathrm{kg})$ with heat stress:

$$
\mathrm{DGV}_{\mathrm{HT} \_ \text {trait }}=\mathbf{W} \hat{\mathbf{b}}_{\mathrm{HT} \_ \text {trait }} \text {, }
$$

where $\mathbf{W}$ is the $i$ animal $\times j$ SNP standardized genotype matrix, and

$$
\mathbf{W}=\left(X_{i j}-2 p_{j}\right) / \sqrt{2 p_{j}\left(1-p_{j}\right)},
$$

where $X_{i j}$ is the $i$ animal $\times j \mathrm{SNP}$ genotype $(0,1$, or 2 for each genotype); $p_{j}$ is the frequency of allele 2 at SNP $j$ (Yang et al., 2010); and $\hat{\mathbf{b}}_{\mathrm{HT} \_ \text {trait }}$ is $\hat{\mathbf{b}}_{\mathrm{HT} \_ \text {milk }}, \hat{\mathbf{b}}_{\mathrm{HT} \_ \text {fat }}$, or $\hat{\mathbf{b}}_{\mathrm{HT} \_ \text {prot }}$, which is the vector of SNP effects for decline of each trait (milk, fat, and protein yield) due to heat stress.

\section{(5) Combination of DGV in each trait}

The following equation was used to calculate DGV in each trait to form a decline in milk production traits due to heat stress:

$\mathrm{DGV}_{\mathrm{HT} \_\mathrm{ASI}}=\mathrm{EW}_{\mathrm{m}} \times \mathrm{DGV}_{\mathrm{HT}_{\text {_milk }}}+\mathrm{EW}_{\text {fat }} \times \mathrm{DGV}_{\mathrm{HT}_{-} \text {fat }}$ $+\mathrm{EW}_{\text {prot }} \times \mathrm{DGV}_{\text {HT_prot }}$,

where $\mathrm{DGV}_{\mathrm{HT} \_\mathrm{ASI}}$ is the decline in the Australian selection index (ASI) in AU\$ per unit increase in THI and $\mathrm{EW}_{\mathrm{m}}=-0.10, \mathrm{EW}_{\text {fat }}=1.79$, and $\mathrm{EW}_{\text {prot }}=6.92$ are the economic weights of milk, fat, and protein yield, respectively, which are used by DataGene to calculate national dairy selection indices in Australia (Byrne et al., 2016). Note that the ASI is a production trait only selection index, but the same weights are also applied in Australian multitrait selection indices that include traits aligning to costs of production.

(6) Expression of HT ABVg

The following equation was used to calculate expression of $\mathrm{HT}$ ABVg:

$\mathrm{HT} \mathrm{ABV}_{\mathrm{g}}=100+5$

$\times\left[\mathrm{DGV}_{\mathrm{HT} \_\mathrm{ASI}}-\operatorname{mean}\left(\mathrm{DGV}_{\mathrm{HT} \_\mathrm{ASI}}\right)\right] / \mathrm{SD}\left(\mathrm{DGV}_{\mathrm{HT} \_\mathrm{ASI}}\right)$,

where the mean and standard deviation were derived from a population that included reference and validation bulls used in this study.
A cohort of 497 Holstein sires born in and after 2006 and 183 Jersey sires born in and after 2007 was used as a validation population. These animals and their daughters were not included in the reference sets. Regardless of year of birth, paternal half-sib sires were placed together in either the reference set or the validation set. The DGV for decline in milk, fat, and protein yield were calculated for validation sires. The reliability for $\mathrm{HT} \mathrm{ABVg} \mathrm{was} \mathrm{assumed} \mathrm{to} \mathrm{be} \mathrm{equivalent} \mathrm{to} \mathrm{the} \mathrm{reli-}$ ability of HT on protein yield, which is similar to the approach used by DataGene to obtain the reliability of ASI (because protein has a greater economic value than milk and fat yield). The reliability was calculated as

$$
\mathrm{REL}_{i}=1-\frac{\mathrm{SE}_{i}^{2}}{\sigma^{2}}
$$

where $\mathrm{REL}_{i}$ is the reliability of DGV of the decline of protein yield with heat stress of individual $i, \mathrm{SE}_{i}^{2}$ is the prediction error variance of individual $i$ (obtained from the genomic best linear unbiased prediction model), and $\sigma^{2}$ is the genomic variance of the decline of protein yield with heat stress.

The HT ABVg ranged from 84 to $112(-4$ to +3 SD) in Holsteins and 86 to 117 ( -3 to +4 SD) in Jerseys (Figure 1). Under this standardized expression, if a bull has a breeding value larger than 100, his daughters will be more heat tolerant than those of the average bull. Likewise, if a bull has a breeding value less than 100, his daughters will be less heat tolerant than those of the average bull.

The reliability of $\mathrm{HT} \mathrm{ABVg}$ in genotyped Holstein bulls with no daughters in the reference set ranged from 16 to $54 \%$ and had a mean of $38 \%$ and a standard deviation of $7 \%$. In Jerseys, the reliability of HT ABVg ranged from 15 to $54 \%$ and had a mean of $38 \%$ and a standard deviation of $9 \%$ (Figure 1b). Although the reference population of Jerseys is much smaller than that of Holsteins, a similar average reliability was achieved, probably because of the smaller effective population size in Jerseys (Hayes et al., 2009). The reliability of HT ABVg is moderate and comparable with that of other economically important traits such as feed saved (mean reliability of $37 \%$ in genotyped Holstein bulls with no daughters; Pryce et al., 2015). Although this level of reliability enables genetic gain to be made for $\mathrm{HT}$, it is desirable to improve the reliability further by increasing the size of the reference population. In this regard, the Genomic Information Nucleus (Ginfo), which includes herds with high-quality phenotype recording, has been established in Australia (Pryce et al., 2017). Our experience shows that the inclusion of Ginfo cows in the reference populations increases reliabilities 
of young genotyped bulls by between 5 and $7 \%$ for Holsteins and between 2 and $3 \%$ for Jerseys, depending on traits (Pryce et al., 2017). For HT, adding 4,711 Holstein and 3,153 Jersey Ginfo cows in the corresponding reference populations improved reliability by 3 and $6 \%$, respectively (Nguyen et al., 2017). As the size of the Ginfo reference population is projected to increase over time, the reliability of $\mathrm{HT} \mathrm{ABVg}$ and many other traits is expected to improve.

Genetic trends show a slight decline in HT over time (Figure 2). This is expected given the unfavorable correlation of HT with milk, fat, and protein yield (Nguyen et al., 2016a). Between the years 1990 and 2011, HT $\mathrm{ABVg}$ declined at the rate of $0.3 \% / \mathrm{yr}$ in both breeds. This indicates that herds in a warmer climate may wish to take steps to prevent a further decline in HT. The best way to achieve this is to have HT included in the multitrait economic selection indices, such as the Australian balanced performance index (Byrne et al., 2016), so that HT can be selected jointly with other economic drivers (Nguyen et al., 2016b).

a)

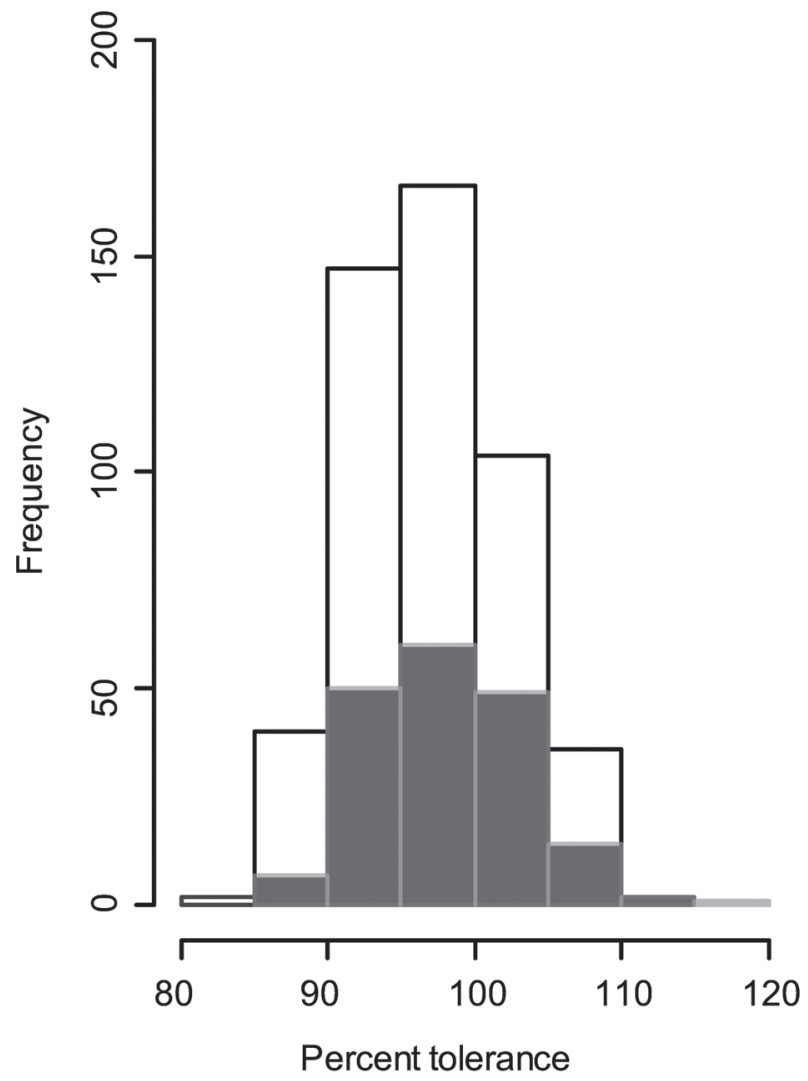

The implementation of HT ABVg is considered an initial stage to improve HT in Australian dairy cattle. It is also possible to calculate conventional $\mathrm{HT}$ ABV using pedigree relationship instead of genomic relationship. This will allow every cow with good-quality herd test records to have an HT breeding value; thus, progress on HT can be monitored at the herd level and animals to breed for replacement can be selected.

It is widely recognized that heat stress negatively affects not only production but also fertility and health traits (Kadzere et al., 2002; Hansen, 2007; Dikmen et al., 2012). Nguyen et al. (2016a) found a favorable correlation between HT tolerance and fertility, suggesting that improvement in HT will help improve fertility. We also envisage that the methods described here could be applied across several health traits, such as mastitis resistance. If genetic variation of $\mathrm{HT}$ on these traits can be quantified, it is possible to breed for more robust dairy cattle that are tolerant to heat stress in terms of health and fertility and capable of producing high milk yield in varying climatic conditions. b)

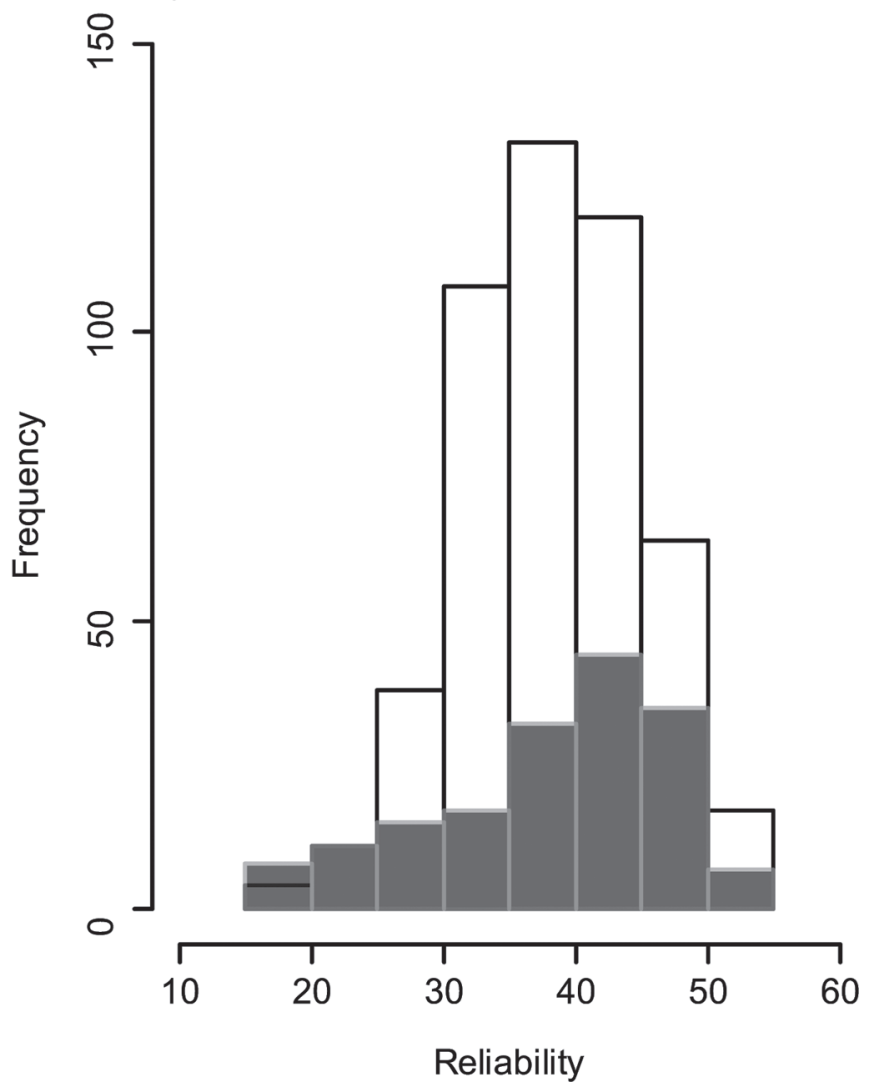

Figure 1. (a) Distribution of Australian genomic breeding values for heat tolerance in 497 Holstein (white bars) and 183 Jersey (gray bars) bulls without daughters in the reference and (b) corresponding reliability. 
a)

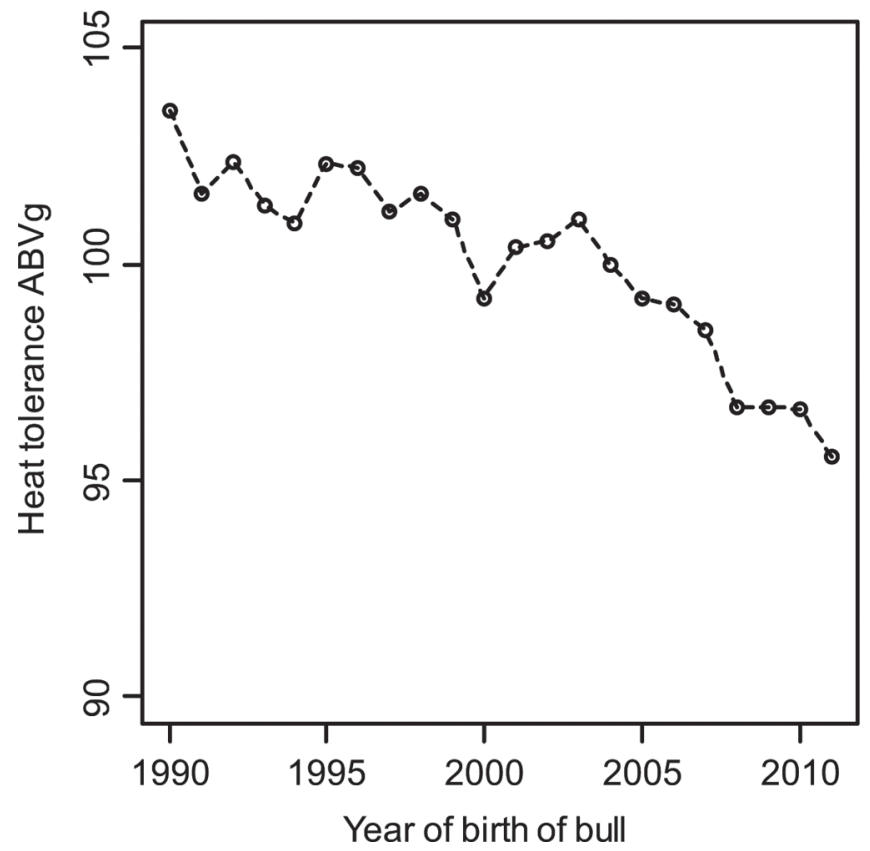

b)

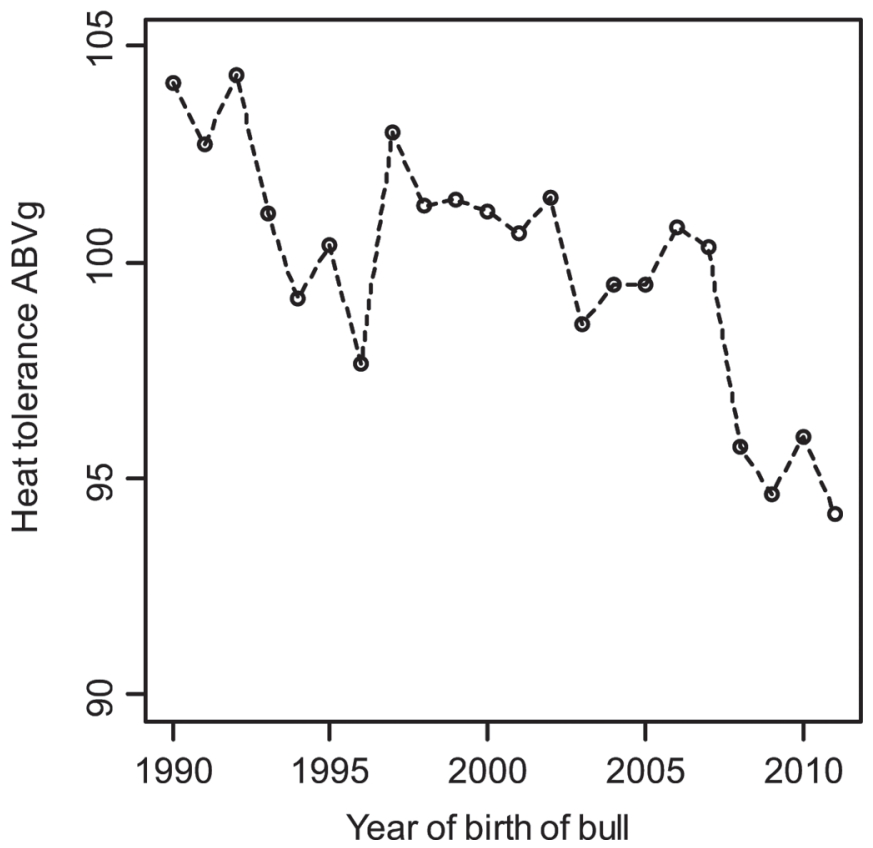

Figure 2. Genetic trend of Australian genomic breeding values (ABVg) for heat tolerance in (a) 2,665 Holstein bulls and (b) 641 Jersey bulls that were born in and after 1990 .

In conclusion, the present study proposes a new measure of genetic merit for the Australian dairy industry: the HT ABVg. This is a genomic-only breeding value that is expressed as the decline in milk, fat, and protein production per unit increase in THI above the threshold where heat stress affects production. Selection for HT is timely to prevent further deterioration in tolerance of heat stress. In this context, DataGene plans to release the HT ABVg in late 2017. The best strategy for achieving an optimal outcome is to select for improvement in HT in combination with other traits that contribute to profitability. Further investigations on genetic variation of HT on health traits and fertility will enable a better understanding of the effects of HT on overall performance of animals and net returns, thereby permitting the selection of more robust animals for a more resilient and profitable industry.

\section{ACKNOWLEDGMENTS}

This study was undertaken as part of the DairyBio program, which is cofunded by the Government of Victoria (Melbourne, Australia) and Dairy Australia (Melbourne, Australia). The authors thank DataGene (Melbourne, Australia) for providing production and genotype data.

\section{REFERENCES}

Beede, D. K., and R. J. Collier. 1986. Potential nutritional strategies for intensively managed cattle during thermal stress. J. Anim. Sci. $62: 543-554$.

Bohmanova, J., I. Misztal, S. Tsuruta, H. D. Norman, and T. J. Lawlor. 2008. Genotype by environment interaction due to heat stress. J. Dairy Sci. 91:840-846.

Byrne, T. J., B. F. S. Santos, P. R. Amer, D. Martin-Collado, J. E. Pryce, and M. Axford. 2016. Breeding objectives and indexes for the Australian dairy industry. J. Dairy Sci. 99:8146-8167.

Dikmen, S., J. B. Cole, D. J. Null, and P. J. Hansen. 2012. Heritability of rectal temperature and genetic correlations with production and reproduction traits in dairy cattle. J. Dairy Sci. 95:3401-3405.

Dikmen, S., and P. J. Hansen. 2009. Is the temperature-humidity index the best indicator of heat stress in lactating dairy cows in a subtropical environment? J. Dairy Sci. 92:109-116.

Garner, J. B., M. Douglas, R. S. O. Williams, W. J. Wales, T. T. T. Nguyen, and B. J. Hayes. 2016. Genomic selection improves heat tolerance in dairy cattle. Nature Scientific Rep. 6:1-8.

Gilmour, A. R., B. J. Gogel, B. R. Cullis, and R. Thompson. 2009. ASReml User Guide Release 3.0. VSN International Ltd., Hemel Hempstead, United Kingdom.

Hansen, P. J. 2007. Exploitation of genetic and physiological determinants of embryonic resistance to elevated temperature to improve embryonic survival in dairy cattle during heat stress. Theriogenology 68:S242-S249.

Hansen, P. J., and C. F. Aréchiga. 1999. Strategies for managing reproduction in the heat-stressed dairy cow. J. Anim. Sci. 77:36-50.

Hayes, B. J., P. J. Bowman, A. C. Chamberlain, K. Verbyla, and M. E. Goddard. 2009. Accuracy of genomic breeding values in multibreed dairy cattle populations. Genet. Sel. Evol. 41:51.

Hayes, B. J., M. Carrick, P. Bowman, and M. E. Goddard. 2003. Genotype $\times$ environment interaction for milk production of daugh- 
ters of Australian dairy sires from test-day records. J. Dairy Sci. $86: 3736-3744$.

Kadzere, C. T., M. R. Murphy, N. Silanikove, and E. Maltz. 2002. Heat stress in lactating dairy cows: A review. Livest. Prod. Sci. 77:59-91.

Nguyen, T. T. T., P. Bowman, M. Haile-Mariam, J. E. Pryce, and B. J. Hayes. 2016a. Genomic selection for heat tolerance in Australian dairy cattle. J. Dairy Sci. 99:2849-2862.

Nguyen, T. T. T., J. B. Garner, P. J. Bowman, M. Haile-Mariam, J. E. Pryce, and B. J. Hayes. 2017. Breeding value for heat tolerance in Australian dairy cattle: A technical platform for implementation. Pages 35-39 in Proc. HERD 17. DataGene, Bendigo, Australia.

Nguyen, T. T. T., B. J. Hayes, and J. E. Pryce. 2016b. A practical future-scenarios selection tool to breed for heat tolerance in Australian dairy cattle. Anim. Prod. Sci. 57:1488-1493.

Pryce, J. E., P. Douglas, C. M. Reich, A. J. Chamberlain, P. J. Bowman, T. T. T. Nguyen, B. A. Mason, C. P. Prowse-Wilkins, G. J. Nieuwhof, T. Hancock, M. Shaffer, and B. J. Hayes. 2016. Reliabilities of Australian dairy genomic breeding values increase through the addition of genotyped females with excellent phenotypes. Proc. Assoc. Admt. Anim. Breed. Genet. 22. In press.

Pryce, J. E., O. Gonzalez-Recio, G. Nieuwhof, W. J. Wales, M. P. Coffey, B. J. Hayes, and M. E. Goddard. 2015. Definition and implementation of a breeding value for feed efficiency in dairy cows. J. Dairy Sci. 98:7340-7350.

Silanikove, N. 1992. Effects of water scarcity and hot environment on appetite and digestion in ruminants: A review. Livest. Prod. Sci. 30:175-194.

St-Pierre, N. R., B. Cobanov, and G. Schnitkey. 2003. Economic losses from heat stress by US livestock industries. J. Dairy Sci 86(Suppl.):E52-E77.

West, J. W. 1998. Nutritional strategies for managing the heat-stressed dairy cow. J. Dairy Sci. 82:21-35.

Yang, J., B. Benyamin, B. P. McEvoy, S. Gordon, A. K. Henders, D. R. Nyholt, P. A. Madden, A. C. Heath, N. G. Martin, G. W. Montgomery, M. E. Goddard, and P. M. Visscher. 2010. Common SNPs explain a large proportion of the heritability for human height. Nat. Genet. 42:565-569. 